\title{
Conjugate additions of furylcuprates to $\alpha$-enones. The effect of the copper precursor and of TMSCI used as additive
}

\author{
Cristian Rodríguez, Álvaro Vázquez, and N. Sbarbati Nudelman \\ Department of Organic Chemistry, Facultad de Ciencias Exactas y Naturales, Universidad de \\ Buenos Aires, Ciudad Universitaria, Pab. II, P. 3, 1428 Buenos Aires, Argentina \\ E-mail:nudelman@qo.fcen.uba.ar
}

Dedicated to Professor Torbjörn Norin on the occasion of his $75^{\text {th }}$ birthday

\begin{abstract}
The addition of organocuprates to $\alpha, \beta$-unsaturated substrates, namely $E$-cinamaldehyde and 2cyclohexen-1-one, was studied in THF. The furan moiety was chosen for the heterocuprate, because the methods for the synthesis of furan derivatives are scarce and they have a strong potentiality for tandem reactions. The performance of $\mathrm{CuBr} ; \mathrm{CuBr} . \mathrm{SMe}_{2}$ and $\mathrm{CuCN}$ as copper precursors was examined: the higher yields of the 1,4-addition product were obtained using $\mathrm{CuCN}$. The reaction with 2-cyclohexen-1-one gave the best results. In some cases, a compound that arises from dehydration of the 1,2-addition product was obtained and its yield increases near $70 \%$ when the reaction is carried out with furyl-lithium in the absence of any copper salt. Addition of up to 6 equivalents of $\mathrm{TMSCl}$ to the reaction mixture of 2-cyclohexen-1-one with furylcuprate at $-78 \mathrm{C}$, leads to a clean addition yielding more than $90 \%$ of the 1,4 -addition product. The only by-product is 2-TMS-furan. The absence of silylated ether of the enolate, is a strong evidence to rule out the cyclic intermediate or transition state that was previously proposed as the mechanism whereby TMSCl (acting as a Lewis base toward the cuprate) accelerates the reaction. Promoting conversion of the initially formed $\pi$-complex to a reactive tetravalent copper species is proposed instead.
\end{abstract}

Keywords: Organocuprates, $\mathrm{TMSCl}$, furyllithium, conjugated addition, $\alpha, \beta$-unsaturated carbonyl compound

\section{Introduction}

Conjugate addition of carbon nucleophiles to $\alpha, \beta$-unsaturated carbonyl compounds via organocuprates is an essential C-C bond forming process in synthetic organic chemistry. ${ }^{1,2}$ Substantial progress is being made also on the use of organocopper in new environmentally 
friendly catalytic industrial procedures, in particular in stereoselective synthesis and also in the development of intriguing new materials. ${ }^{3,4}$ It is remarkable the broad field in which the conjugated addition reactions are currently applied, they usually represent a key step in the synthesis of very valuable compounds, as it is the case of prostaglandins, ${ }^{5}$ and the antiinflammatory drug $( \pm)$-Rolipram, ${ }^{6}$ and every day a new progress is achieved. ${ }^{7}$

Since we are currently developing new tandem reactions involving organometallic compounds, ${ }^{8}$ the general objective of our study was to examine the potentiality of organocuprates to be involved in this kind of reactions that constitute one of the most powerful synthetic strategies developed for building complex molecules from rather simple ones in a minimum number of operations. ${ }^{9}$

The modern era of organocopper chemistry was initiated by the seminal works of House and Whitesides, ${ }^{10}$ when they demonstrated that $\mathrm{Me}_{2} \mathrm{CuLi}$.LiI reacts with $\alpha$-enones to give 1,4 addition products. In spite of their intensive use in organic synthesis, the structures and mechanism of reaction of these useful organocopper reagents are still no well understood. In the '80s Lipshutz et al. reported that the reaction of $\mathrm{CyI}(\mathrm{Cy}=$ cyclohexane $)$ with the reagent prepared from two equivalents of $\mathrm{BuLi}$ and one equivalent of $\mathrm{CuCN}$ gave a quantitative yield of butylcyclohexane. They claimed that that was a new kind of cuprate species, they called them "higher order cyanocuprates" symbolized as " $\mathrm{R}_{2} \mathrm{Cu}(\mathrm{CN}) \mathrm{Li}_{2}{ }$. ${ }^{11}$ Since then, although no definitive spectroscopic or structural evidence was presented, "the postulate of a tricoordinate, dianionic copper $\sigma$-bond by cyanide continues to decorate the literature", according to Snyder and Bertz. ${ }^{12}$ The "higher order cyanocuprate" concept was then amended by suggesting the existence of a complex in which the cuprate is $\pi$-bonded to cyanide. ${ }^{13}$ Solid state structure of $\left({ }^{\mathrm{t}} \mathrm{BuCu}{ }^{\mathrm{t}} \mathrm{Bu}(\mathrm{thf})(\mathrm{pmdeta}){ }_{2} \mathrm{CN}\right)$ determined by Boche et al. ${ }^{14}$ shows a linear cuprate anion ${ }^{\mathrm{t}} \mathrm{Bu}-\mathrm{Cu}-$ ${ }^{t} \mathrm{Bu}$ and an almost linear $\mathrm{Li}-\mathrm{CN}-\mathrm{Li}^{+}$ion, that are separated from each other. It is not possible to differentiate the $\mathrm{C}$ and the $\mathrm{N}$ of $\mathrm{CN}$. Boche et al. also determined the first structure of a "lower order" cyanocuprate, i.e. the ${ }^{\mathrm{t}} \mathrm{Bu}$ cuprate: ${ }^{\mathrm{t}} \mathrm{BuCu}(\mathrm{CN}) \cdot\left(\mathrm{OEt}_{2}\right)_{2}$, where a $\mathrm{CuCN}$ bond was found.

Further solid-state structure of 2-dimethylaminobenzyl cyanocuprate (2$\left.\mathrm{Me}_{2} \mathrm{NCH}_{2} \mathrm{C}_{6} \mathrm{H}_{4} \mathrm{CH}_{2}\right)_{2} \mathrm{CuLi}_{2}(\mathrm{CN})(\mathrm{THF})_{4}$ by Krause ${ }^{15}$ shows that the cuprate exists as a polymeric zigzag chain with alternating $\mathrm{Ar}_{2} \mathrm{Cu}-$ and $\mathrm{Li}-\mathrm{CN}-\mathrm{Li}^{+}$ions. Also here, a linear cuprate anion and an almost linear $\mathrm{Li}-\mathrm{CN}-\mathrm{Li}^{+}$are found, which are completely separated from each other. Intensive research on organocopper reactions have shown that results are highly dependent on several parameters such as: the copper precursor $(\mathrm{CuX})$; the active organometallic ( $\mathrm{RLi}, \mathrm{RMgX}, \mathrm{RZn}$, $\mathrm{RNa}$ ); the stoichiometry (catalytic $\mathrm{Cu}, 1: 1,2: 1 ;<2: 1 \mathrm{RLi}$ ); the solvent (THF, ether, $\mathrm{Cl}_{2} \mathrm{CH}_{2}$, dimethyl sulfide); the additive (TMSCl, HMPA, phosphines); the dummy ligand (alkynyl, thienyl, TMSM); and the experimental variables such as, cuprate excess, temp., time, work up. In the present work, the active organometallic was organolithium, and the solvent THF. The effects of copper precursor, temperature and time of reaction were examined, as well as the use of TMSCl as additive. The purpose of the work was, first of all, to examine the reactivity of the organocuprate prepared from $\mathrm{CuCN}, \mathrm{CuBr}$; and $\mathrm{CuBr} \cdot \mathrm{SMe}_{2}$ and, secondly, trying to use 
heterocyclic compounds, since these moieties present an interesting potentiality for tandem reactions and methods for their synthesis are scarce.

\section{Results and Discussion}

\section{The substrates}

In the first attempt $E$-cinnamaldehyde, 1, was chosen as substrate for the Michael addition, due to its potential to undergo further synthetic sequences. A general scheme of the reaction using the furylheterocuprate, 2 , is shown by equation 1 .

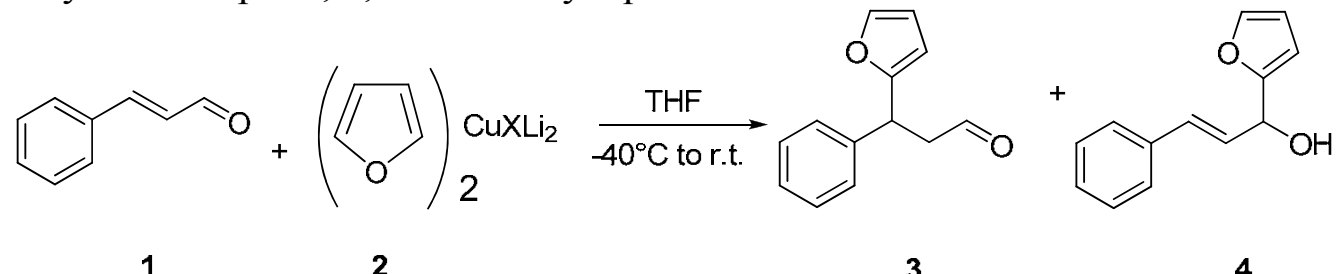

Methodologies involving heterocuprates derived from heterocyclic compounds are scarce, therefore, two different ways of preparation for the furylcuprate were examined.

Method A. The heterocuprate was formed "in situ" from furan and butyllithium, as shown by equation 2 .

$$
\begin{aligned}
& \mathrm{Cux}+2\left\langle\prod_{\mathrm{O}}+2 \mathrm{BuLi} \underset{-78^{\circ} \mathrm{C}, 60 \mathrm{~min} .}{\stackrel{\mathrm{THF}}{\longrightarrow}} \mathbf{2}\right. \\
& \begin{array}{lll}
5 & 6 & 7
\end{array}
\end{aligned}
$$

Method B. The furylcuprate, was obtained from the reaction of $\mathrm{CuX}$ and furyllithium previously prepared, as depicted by equation 3 .

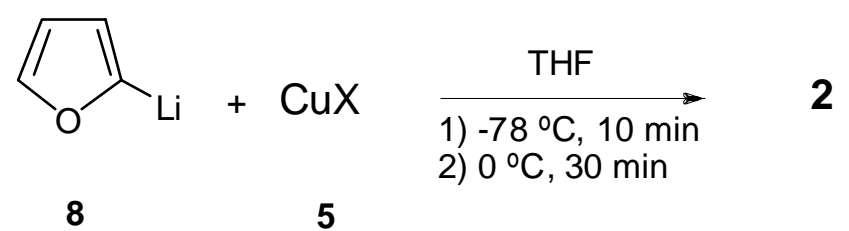

Since method B afforded the best results, under the conditions described in the experimental section, all reactions gathered in the tables were carried out under these standard conditions.

\section{The copper precursors}

When organocuprates were introduced in synthetic methodology by House and Whitesides ${ }^{10}$ and shortly after by Corey and Posner, ${ }^{16} \mathrm{CuI}$ was adopted as the routine precursor. Other precursors 
were advocated lately, such as: $\mathrm{CuBr} . \mathrm{SMe}_{2} ;{ }^{17} \mathrm{CuCN}^{\text {Error! Bookmark not defined. }}$ and $\mathrm{CuOTf}$ (Tf:triflate), ${ }^{18}$ the most popular being the $\mathrm{Br}$ or $\mathrm{CN}$ salts. These precursors have not been compared in side-by-side reaction using heterocyclic compounds, therefore we prepared a series of furylcuprates from some widely used copper salts and examined their behavior in the reaction with $E$-cinnamaldehyde, 1, and also with 2-cyclohexen-1-one, 9, the expected product being 10 and 11, as depicted in the equation 4 .

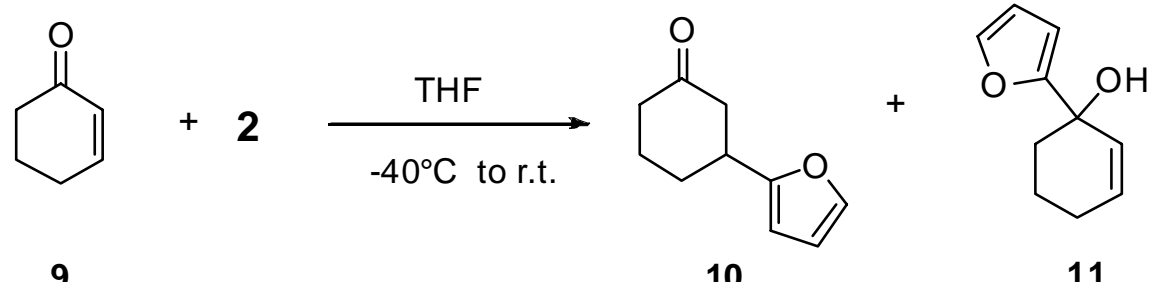

Working under standardized conditions detailed in the Experimental Section, the results shown in Table 1 were obtained.

Table 1. Reactions of furylcuprate with $\alpha, \beta$-unsaturated carbonyl compounds in THF at $-40{ }^{\circ} \mathrm{C}$ to room temperature. Effect of the copper salt precursors

\begin{tabular}{|c|c|c|c|c|}
\hline Entry & Precursor Cu salt & $\alpha, \beta$-Unsaturated substrate & $\%$ Yield $^{\mathrm{a}} 1,4$ & $\%$ Yield $^{\mathrm{a}} 1,2$ \\
\hline \multirow{2}{*}{1} & \multirow{2}{*}{$\mathrm{CuBr}$} & (a) $\boldsymbol{E}$-cinnamaldehyde & $35^{\mathrm{b}}$ & $50^{b}$ \\
\hline & & (b) 2-cyclohexen-1-one & 60 & 20 \\
\hline \multirow{2}{*}{2} & \multirow{2}{*}{$\mathrm{CuBr} \cdot \mathrm{SMe}_{2}$} & (a) $\boldsymbol{E}$-cinnamaldehyde & $70^{b}$ & $10^{b}$ \\
\hline & & (b) 2-cyclohexen-1-one & 80 & 10 \\
\hline \multirow{2}{*}{3} & \multirow{2}{*}{$\mathrm{CuCN}$} & (a) $\boldsymbol{E}$-cinnamaldehyde & $70^{b}$ & 0 \\
\hline & & (b) 2-cyclohexen-1-one & 90 & 5 \\
\hline
\end{tabular}

${ }^{a}$ Yields measured by GC using internal standard. ${ }^{b}$ The products decomposed easily. All reactions were performed using 1equiv. of $\alpha, \beta$-unsaturated substrate and 1 equiv. of furylcuprate.

The reaction using E-cinnamaldehyde as $\alpha, \beta$-unsaturated substrate shows some side reactions: the cinnamic alcohol and bifuran are the most important by-products. The alcohol can be produced by the reduction of the carbonyl group, which is a common undesirable side reaction in the addition of organolithiums to carbonyl compounds. Bifuran is produced by selfcoupling of unreacted furyllithium, probably due to the incomplete generation of the heterocuprate.

Low solubility of $\mathrm{CuBr}$ in organic solvents is probably the cause of the poor performance of the salt. Nevertheless, in all cases the conversion of $E$-cinnamaldehyde was incomplete; this seems to suggest that other variables besides the copper precursor could be involved in this reaction. At first glance, it is clear the better performance of $\mathrm{CuCN}$ over the other precursors, 
very clean reactions are observed even working with $E$-cinnamaldehyde; though the best yield was afforded by 2-cyclohexen-1-one. When using $\mathrm{CuBr} \cdot \mathrm{SMe}_{2}$ good yields for the 1,4 addition product are obtained, but still the conversion of $E$-cinnamaldehyde is poor and in the case of 2cyclohexen-1-one the yield of 1,2 product was significant. The E-cinnamaldehyde is more sensitive to the reaction conditions which makes difficult the interpretation of the results; as an example, Table 2 shows a strong dependence on temperature. As a referee pointed out Cinnamaldehyde is a tricky substrate as 1,4 addition must overcome the aryl conjugation, whereas 1,2 addition lack of enolate stabilization“ Efforts to find the best reaction conditions, without loosing performance, are still in progress.

Table 2. Reactions of furylcuprate with $\boldsymbol{E}$-cinnamaldehyde in $\mathrm{THF}^{\mathrm{a}}$

\begin{tabular}{cccc}
\hline Entry & Temp. & \% Yield $(1,2: 1,4)$ & $\begin{array}{c}\text { Remaining } \\
\text { Cinnamaldehyde (\%) }\end{array}$ \\
\hline 1 & -78 & no reaction & 100 \\
2 & -50 to -20 & $20: 80$ & 56 \\
3 & -50 to 0 & $12: 88$ & 0 \\
\hline
\end{tabular}

${ }^{\mathrm{a} U}$ sing $\mathrm{CuCN}$ as precursor salt. ${ }^{\mathrm{b}}$ Yields measured by GC using internal standard. All reactions were performed using 1 equiv. of $\alpha, \beta$-unsaturated substrate and 1 equiv. of furylcuprates.

\section{A dehydration product}

In the reactions with 2-cyclohexen-1-one, the $\alpha, \beta$-unsaturated substrate, the most important byproduct observed is a compound that seems to be the dehydration product of a 1,2 addition. Trying to shine some light on this side-reaction, the addition was carried out in the absence of copper salt, so the reaction should occur directly as a conventional addition, giving a major yield of the 1,2-addition product. Taking into account that dehydration could occur during the workup, different ways of quenching the reaction were examined; the results obtained under optimized conditions are shown in Table 3.

Table 3. Addition of furyllithium to 2-cyclohexen-1-one, in $\mathrm{THF}$ at $-78^{\circ} \mathrm{C}$ to r.t.

\begin{tabular}{cccc}
\hline Entry & $\begin{array}{c}\text { Dehydrated 1,2-addition } \\
\text { Product, } \mathbf{1 2}{ }^{\mathrm{a}}(\mathbf{\%})\end{array}$ & Michael Addition ${ }^{\mathrm{a}}(\%)$ & "Quenching \\
\hline 1 & 69.2 & 25.4 & $\mathrm{NH}_{4} \mathrm{Cl}$ \\
2 & 65.5 & 30.2 & $\mathrm{MeOH}$ \\
3 & 61.6 & 25.4 & $\mathrm{H}_{2} \mathrm{O}$ \\
\hline
\end{tabular}

${ }^{a}$ Yields measured by GC using internal standard. All reactions were performed using 1equiv. of furillithium and 1 equiv. of 2-cyclohexen-1-one. 
As shown in Table 3, the yield of products is independent of the working-up procedure, a rather important amount of the 1,4-addition product was observed even when the reaction was run in the absence of any copper, this could suggest that the steric effects between furyl and the hydroxyl group in the substrate could somehow hinder the 1,2-addition. GC-MS studies of the main reaction product show a molecular ion (base peak) with a $\mathrm{m} / \mathrm{z}=146$, the $\mathrm{M}^{+}$and the rest of the fragment ions, are consistent with a dehydrated 1,2-addition product, the 2-(2-furyl)-1,3cyclohexadiene, 12, as depicted in Scheme 1.

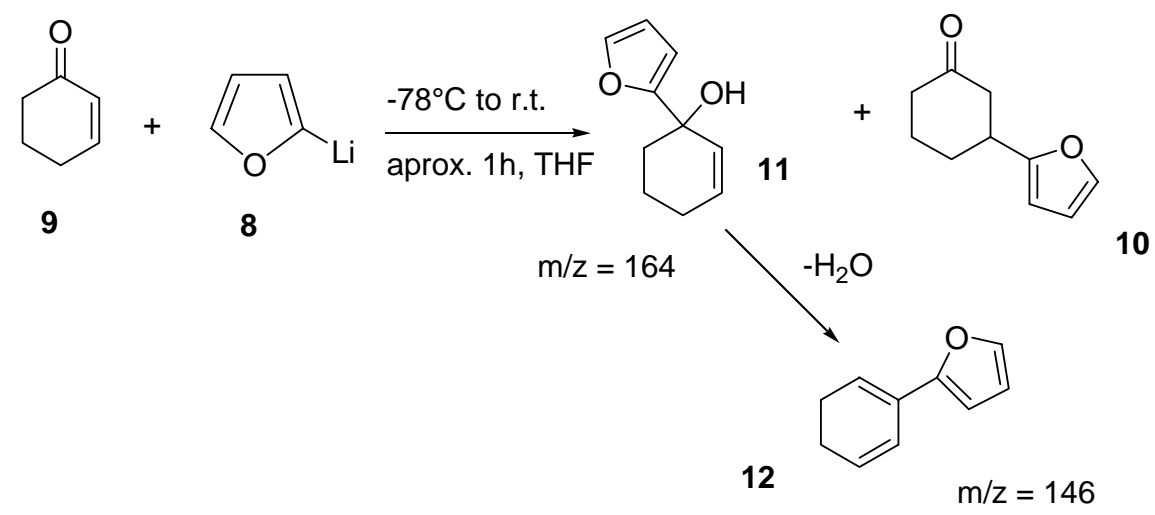

\section{Scheme 1}

Though some dehydration occurring during the GC analysis could not be fully neglected, several GC conditions (such as different columns, temperature programs, etc.) were tested but not changes in the result were observed.

\section{Reaction in the presence of additives}

Exploring the scope of the 1,4-addition reaction, a new strategy: The addition of a Lewis acid as an additive was examined. After the remarkable observation by Corey and Boaz ${ }^{19}$ that TMSCl, 13, could change both the rate and the stereochemistry of organocuprate reactions, several groups throughout the world studied this effect. ${ }^{20 \mathrm{a}-\mathrm{c}}$ Nevertheless, $\mathbf{1 3}$ as additive has not been reported in additions using heterocycles as heterocuprates. The reaction was carried out by Method B with a few minor changes. According to the literature, $\mathbf{1 3}$ was added to the reaction mixture after the formation of the organocuprate but previous to the aggregate of the $\alpha, \beta$ unsaturated substrate. An outline of the reaction can be seen in equation 5 .

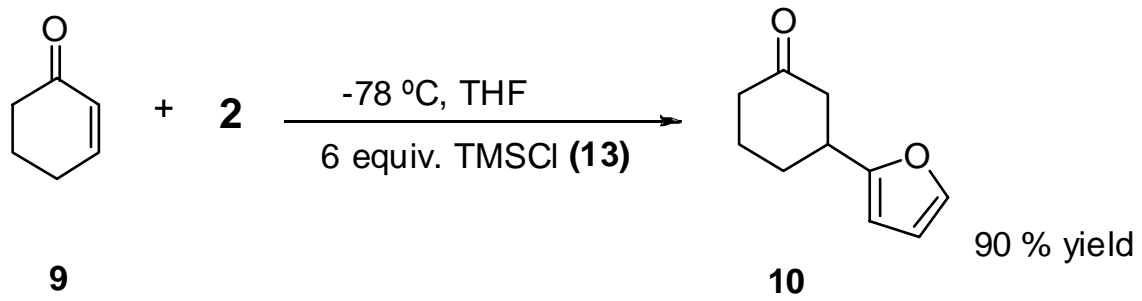


The effect of several variables such as temperature, time of reaction and precursor salt were examined. As can be observed in Table 4 the yield was usually higher than $90 \%$ when the reaction is allowed to complete ( $1 \mathrm{~h}$ or more). The conversion of 2-cyclohexen-1-one is about $80 \%$. The only by-product is 2-TMS-Furano, what make sense since 6 equiv. of $\mathbf{1 3}$ are used and some excess of furan is present. Anyway, it is very interesting the fact that only the 1,4-addition product was obtained. $\mathbf{1 0}$ was isolated as a pure compound from the reaction mixture and the structure was confirmed by NMR and MS.

Table 4. Addition of furylheterocuprate to 2-cyclohexen-1-one, in THF at -78 C, in the presence of $\mathrm{TMSCl}$ (6 equiv) as additive

\begin{tabular}{cccccccc}
\hline Entry & $\begin{array}{c}\text { Time } \\
(\text { min. })\end{array}$ & Copper salt & $\begin{array}{c}\text { \% Yield } \\
(1,4)\end{array}$ & Entry & $\begin{array}{c}\text { Time } \\
(\text { min. })\end{array}$ & $\begin{array}{c}\text { Copper } \\
\text { salt }\end{array}$ & $\begin{array}{c}\text { \% Yield } \\
(1,4)\end{array}$ \\
\hline $\mathbf{1}^{\mathbf{b}}$ & 60 & $\mathrm{BrCuSMe}_{2}$ & 96.5 & $\mathbf{6}^{\mathbf{c}}$ & 45 & $\mathrm{CuCN}$ & 87.7 \\
$\mathbf{2}^{\mathbf{b}}$ & 60 & $\mathrm{CuCN}$ & 98.3 & $\mathbf{7}^{\mathbf{c}}$ & 60 & $\mathrm{CuCN}$ & 95.1 \\
$\mathbf{3}^{\mathbf{c}}$ & 3 & $\mathrm{CuCN}$ & 67.0 & $\mathbf{8}^{\mathbf{c}}$ & 90 & $\mathrm{CuCN}$ & 95.8 \\
$\mathbf{4}^{\mathbf{c}}$ & 15 & $\mathrm{CuCN}$ & 80.7 & $\mathbf{9}^{\mathbf{c}}$ & 120 & $\mathrm{CuCN}$ & 95 \\
$\mathbf{5}^{\mathbf{c}}$ & 30 & $\mathrm{CuCN}$ & 86.1 & $\mathbf{1 0}^{\mathbf{C}}$ & 180 & $\mathrm{CuCN}$ & 96 \\
\hline
\end{tabular}

${ }^{\mathrm{a}}$ Yields measured by GC using internal standard. ${ }^{\mathrm{b}}$ Reaction at $-78{ }^{\circ} \mathrm{C}$, ${ }^{\mathrm{c}}$ Reaction at $-78{ }^{\circ} \mathrm{C}$ to r.t. All reactions were performed using 1 equiv. of 2-cyclohexen-1-one, 1 equiv. of furylcuprates and 6 equiv. of TMSCl.

In spite of the abundant research, the mechanism whereby $\mathbf{1 3}$ influences the rate and stereochemistry of organocuprates reactions is still controversial. Corey et al. proposed a mechanism in which $\mathbf{1 3}$ directly silylates the $\mathrm{O}$ of the enone in a " $\mathrm{d}-\pi *-$ complex". A second scenario invokes that $\mathbf{1 3}$ activates conjugate addition of copper reagents as a Lewis acid in a TMS-Cl-substrate interaction; ${ }^{20 a}$ while an opposite interpretation suggests that an interaction between TMS-Cl and $\mathrm{R}_{2} \mathrm{CuLi}$ may exist where TMS-Cl acts as a Lewis base toward the cuprate, giving a cyclic intermediate. ${ }^{21}$ The other salient feature of this proposed mechanism is that the TMS enol ether (which is frequently a commonly observed side-product under these conditions) is formed directly via such a cyclic intermediate. Nevertheless, more recent studies with 2cyclohexen-1-one and $\mathrm{Bu}_{2} \mathrm{CuLi}$.LiI showed that $\mathbf{1 3}$ alone is not able to silylate the cuprate-enone complex in ether and is able to silylate it only to a limited extent (around 25\%) in THF; on the other hand, the silyl-ether is easily formed when using a more reactive silylating agent as TMSCl + HMPA. $^{22}$ 


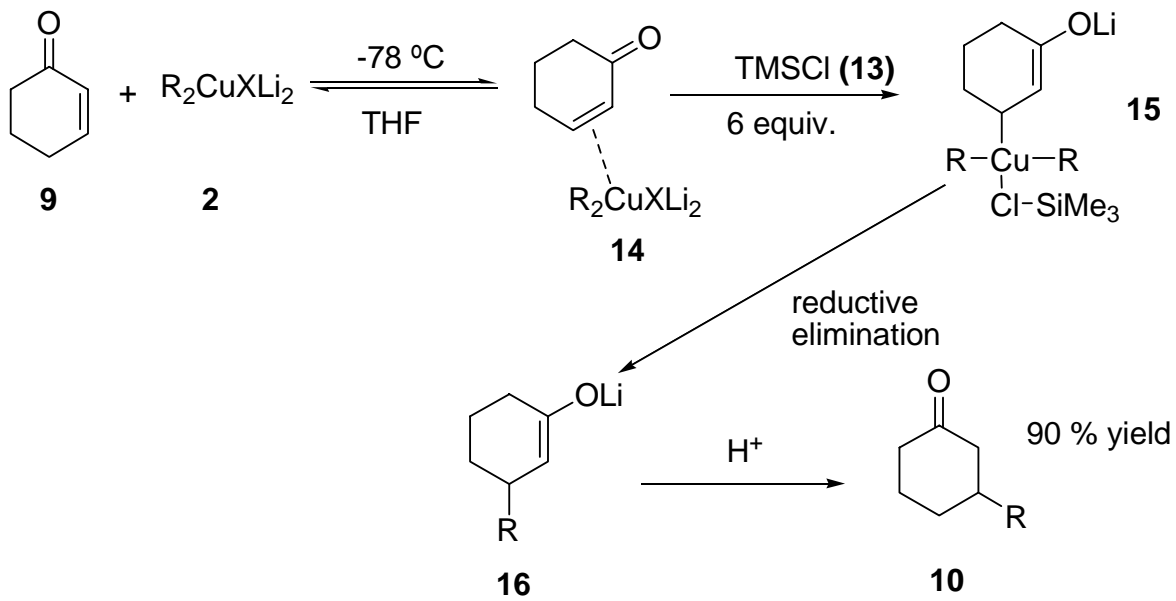

\section{Scheme 2}

In the present work, the 1,4-addition product is formed in yields around $90 \%$ or higher, while the silyl ether of the enolate is not observed. The only silylated product found is the furyl-TMS which is expected taking into account the unreacted furan. The absolute absence of any silyl ether in the present study allows us to rule out a mechanism in which the cyclic intermediate or transition state leads directly to the TMS enol ether, as it was previously proposed. Instead, the effect of the $\mathbf{1 3}$ additive would be promoting conversion of the initially formed $\pi$-complex 14 to a reactive tetravalent copper species, 15, capable of rapid reductive elimination, 16, to the product (Scheme 2). As suggested by Snyder et al. "the key observation is that $\mathbf{1 3}$ stabilize the transition state more than it does the ground state (lower activation energy)". ${ }^{22}$ When HMPA is present, it stabilizes the ground state more (higher activation energy) and a higher production of the silyl ether is observed. Thus, formation of the tetravalent copper species enhances the rate of the 1,4-cuprate addition, and this is the only product obtained under the present reaction conditions.

\section{Experimental Section}

General Procedures. All reactions involving organolithium reagents were carried out by using standard techniques for the manipulation of air- and water-sensitive compounds. ${ }^{23}$ The products were characterized by GC-MS spectrometry (using a gas chromatograph coupled to the BG Trio2 mass spectrometer), and or nuclear magnetic resonance spectroscopy (determined on a Brucker 200 spectrometer operating at $200 \mathrm{MHz}$ for ${ }^{1} \mathrm{H}$ and $50 \mathrm{MHz}$ for ${ }^{13} \mathrm{C}$ and a Brucker 500 spectrometer operating at $500 \mathrm{MHz}$ for ${ }^{1} \mathrm{H}$ and $125 \mathrm{MHz}$ for ${ }^{13} \mathrm{C}$ ) The ${ }^{1} \mathrm{H}$ chemical shifts are referenced relative to TMS, and the ${ }^{13} \mathrm{C}$ chemical shifts are referenced relative to $\mathrm{CDCl}_{3}$ at $\delta=$ 77.0. The GC analyses were carried out on a 5890 Hewlett-Packard Series II Plus gas chromatograph, (Agilent Technologies, Avondale, PA) equipped with a FID system and a $30 \mathrm{~m} \mathrm{x}$ 
$0.25 \mathrm{~mm}$ HP-5 (Phenyl-methylsilicone 5\%) capillary column (coated with a $0.25 \mu \mathrm{m}$ thickness film). High purity nitrogen was the carrier gas; the column head pressure was controlled at 4 Psi. The temperature program was: $80^{\circ} \mathrm{C}$ for $1 \mathrm{~min}, 10^{\circ} \mathrm{C} / \mathrm{min}$ to $280^{\circ} \mathrm{C}$, and hold for $10 \mathrm{~min}$. Under these conditions the observed retention times, Rt, are as follows: Rt (min.) (1) 11.6 ; (3) 18.5 ; (4) 17.6; (9) 6.9; (12) 11.3; (10) 12.3. The injector and detector temperature were $280{ }^{\circ} \mathrm{C}$ and $300{ }^{\circ} \mathrm{C}$ respectively. Elemental analysis were performed in a Exeter CE 440 (CHNS) Elemental Analyzer

Materials. Tetrahydrofuran (THF) was purified by distillation under nitrogen from dark blue solutions of sodium/benzophenone ketyl immediately prior to use. Benzophenone (Aldrich) was 99\% pure and was used after recrystallization from ethanol. Commercial $E$-cinnamaldehyde and 2-cyclohexen-1-one were distilled prior to use. Butyllithium, was prepared as previously described. ${ }^{24}$ The concentration of BuLi was determined by the double titration method described before. ${ }^{25}$ Commercial $\mathrm{CuCN}$ (Aldrich 99\%) and $\mathrm{CuBr} \cdot \mathrm{SMe}_{2}$ (Aldrich 99\%) were used without any further purification. $\mathrm{CuBr}$ was prepared similarly to the way described for $\mathrm{CuCl}^{26} \mathrm{All}$ glassware, syringes, and needles were dried in an oven at $130{ }^{\circ} \mathrm{C}$ overnight and cooled in a desiccator.

\section{Conjugated addition reaction of 2 -lithiofuran to $\alpha, \beta$-insaturated carbonyl compound}

Method A. The copper precursor $5(1 \mathrm{mmol})$ was weighed into a round-bottomed flask with a magnetic stirbar, protected from light and capped with a septum. The flask was evacuated, and filled with dry argon, alternatively several times. Dry THF $(2 \mathrm{~mL})$ was added and the resulting suspension was cooled to $-78{ }^{\circ} \mathrm{C}$, under stirring. Furan 6 (2 mmol in THF) was added, and the mixture was stirred for $5 \mathrm{~min}$. Then $2 \mathrm{mmol}$ of BuLi 7 was added dropwise and the mixture was stirred until the complete dilution of the copper salt (30 to 60 minutes), the mixture was heated to $-40{ }^{\circ} \mathrm{C}$ and the carbonyl compound 1 or 9 ( $\left.1 \mathrm{mmol}\right)$ was added dropwise; the mixture was allowed to warm to room temperature and then the reaction was quenched by the addition of $3 \mathrm{M}$ aqueous $\mathrm{NH}_{4} \mathrm{Cl}(\mathrm{pH} \approx 5)$. The reaction mixture was extracted with dichloromethane. The organic extract was dried (anhydrous $\mathrm{Na}_{2} \mathrm{SO}_{4}$ ) and the solvent distilled under vacuum.

Method B. Furan $6(2.5 \mathrm{mmol}$ in $3 \mathrm{ml} \mathrm{THF})$ was added to a purged septum-capped roundbottomed flask, protected from light, under argon atmosphere and cooled to $-78{ }^{\circ} \mathrm{C}$ in an acetone/dry ice bath. After $5 \mathrm{~min}$. BuLi $7(2 \mathrm{mmol})$ were added dropwise under stirring. After 10 min. at $-78^{\circ} \mathrm{C}$ the mixture was heated at $0{ }^{\circ} \mathrm{C}$ and hold for $30 \mathrm{~min}$. The mixture was transferred via canula to a purged septum-capped round-bottomed flask containing $1 \mathrm{mmol}$ of copper salt 5 in $3 \mathrm{ml} \mathrm{THF}$ at $-78{ }^{\circ} \mathrm{C}$ under stirring condition. The mixture was stirred until the complete dilution of the copper salt (30 to $60 \mathrm{~min}$.). The reaction proceeds as described for method A. Best result was obtain with this method: $90 \%$ yield of conjugated addition $\mathbf{1 0}$ product with only $5 \%$ of 1,2 addition product 11, using $\mathrm{CuCN}$ as a precursor salt and 2-Cyclohexene-1-one as substrate for the reaction. 


\section{Conjugated addition reaction using TMSCI}

Using, either Method A or B for the preparation of furillithium 8 we continued as follow: After the formation of organocuprate 2 at $-78^{\circ} \mathrm{C}, 6$ equiv. of TMSCl 13 were added to the reaction mixture, stirred for $10 \mathrm{~min}$. then it was heated to $-40{ }^{\circ} \mathrm{C}$ (for standard condition) and the carbonyl compound 1 or 9 ( $1 \mathrm{mmol})$ was added dropwise; the mixture was allowed to warm to room temperature and then quenched by the addition of $3 \mathrm{M}$ aqueous $\mathrm{NH}_{4} \mathrm{Cl}$. Work up follow as usual.

Only 1,4-addition product 10 was obtain in a 90\% yield, using $\mathrm{CuCN}$ and 2-Cyclohexene-1-one. 3-Phenyl-2-propenal (1). ${ }^{27} \mathrm{H}-\mathrm{NMR}\left(200 \mathrm{MHz}, \mathrm{CDCl}_{3}\right) \delta(\mathrm{TMS}), 6.6(1 \mathrm{H}, \mathrm{dd}, \mathrm{J}=15 \mathrm{~Hz}, 7.6$ $\mathrm{Hz}), 7.4-7.5(6 \mathrm{H}, \mathrm{m}), 7.53(1 \mathrm{H}, \mathrm{d}, \mathrm{J}=15 \mathrm{~Hz}), 9.69(1 \mathrm{H}, \mathrm{d}, \mathrm{J}=7.6) .{ }^{13} \mathrm{C}-\mathrm{NMR}\left(200 \mathrm{MHz}, \mathrm{CDCl}_{3}\right)$ $\delta 193.6,152.7,134.0,131.2,129.1,128.6,128.5 ; \mathrm{MS}(70 \mathrm{eV}): \mathrm{m} / \mathrm{z}=131(100 \%), 103,77,63$, 51.

3-Phenyl-3-(2-furyl)-propenal (3). Unstable oil. ${ }^{1} \mathrm{H}-\mathrm{NMR}\left(200 \mathrm{MHz}, \mathrm{CDCl}_{3}\right) \delta$ (TMS), 9.7 $(1 \mathrm{H}, \mathrm{t}), 7.1-7.5(5 \mathrm{H}, \mathrm{m}), 7.3(1 \mathrm{H}, \mathrm{dd}), 6.2(1 \mathrm{H}, \mathrm{t}), 5.9(1 \mathrm{H}, \mathrm{dd}), 4.2(1 \mathrm{H}, \mathrm{t}), 2.6-2.8(2 \mathrm{H}, \mathrm{ddd}){ }^{13} \mathrm{C}-$ NMR $\left(200 \mathrm{MHz}, \mathrm{CDCl}_{3}\right) \delta 155.1,142.5,136.3,131.9,128.6,128.0,126.7,110.4,106.8,68.5$, 68.0, 25.6; MS (70eV): m/z = 200 (35), 172(15), 153(14), 152(13), 128(20), 116(8), 115(25), 105(100), 95(51), 94(20), 91(25), 77(59), 40(84). Elemental Anal. Calc for $\mathrm{C}_{13} \mathrm{H}_{12} \mathrm{O}_{2}: \mathrm{C}, 77.98$; H, 6.04; O, 15.98. Found: C, 78.15; H, 6.11; O, 15.74 .

3-Phenyl-1-(2-furyl)-1-hydroxy-2-propene (4). Unstable oil. ${ }^{1} \mathrm{H}-\mathrm{NMR}\left(200 \mathrm{MHz}, \mathrm{CDCl}_{3}\right) \delta$ (TMS) $7.5(1 \mathrm{H}, \mathrm{dd}), 7.1-7.4(5 \mathrm{H}, \mathrm{m}), 6.7(1 \mathrm{H}, \mathrm{d}), 6.4-6.5(2 \mathrm{H}, \mathrm{m}), 6.1(1 \mathrm{H}, \mathrm{dd}), 5.2(1 \mathrm{H}, \mathrm{m}), 2.5$ $(1 \mathrm{H}, \mathrm{s}) .{ }^{13} \mathrm{C}-\mathrm{NMR}\left(200 \mathrm{MHz}, \mathrm{CDCl}_{3}\right) \delta 151.4,142.9,133.9,131.9,130.2,129.6,128.4,128.4$, 126.9, 126.9, 113.2, 104.8, 71.0; MS (70eV): m/z: 200(20), 182(12), 158(34), 141(14), 129(45), 128(100), 127(30), 115(85), 102(13), 91(59), 77(26), 40(92). Elemental Anal. Calc for $\mathrm{C}_{13} \mathrm{H}_{12} \mathrm{O}_{2}$ : C, 77.98; H, 6.04; O, 15.98. Found: C, 77.52; H, 6.23; O, 16.25.

2-Cyclohexene-1-one (9). ${ }^{28} \mathrm{H}-\mathrm{NMR}\left(200 \mathrm{MHz}, \mathrm{CDCl}_{3}\right) \delta$ (TMS) $7.03(1 \mathrm{H}, \mathrm{d}, \mathrm{J}=10.3 \mathrm{~Hz}), 6$ $(1 \mathrm{H}, \mathrm{d}, \mathrm{J}=10.3 \mathrm{~Hz}), 2.4(4 \mathrm{H}, \mathrm{m}), 2(2 \mathrm{H}, \mathrm{m}) .{ }^{13} \mathrm{C}-\mathrm{NMR}\left(200 \mathrm{MHz}, \mathrm{CDCl}_{3}\right) \delta 200,150.8,130$, 38.3, 25.1, 22.7. MS (70eV): m/z: 96(65), 69(10), 68(100), 55(14), 53(10), 42(22), 41(17), 40(49).

2-(2-Furyl)-1,3-cyclohexadiene (12). ${ }^{1} \mathrm{H}-\mathrm{NMR}\left(200 \mathrm{MHz}, \mathrm{CDCl}_{3}\right) \delta$ (TMS) 7.45 (1H, dd), 6.4 $(1 \mathrm{H}, \mathrm{d}), 6.3(1 \mathrm{H}, \mathrm{dd}), 6.1(1 \mathrm{H}, \mathrm{dd}), 5.78(1 \mathrm{H}, \mathrm{d}), 5.5(1 \mathrm{H}, \mathrm{m}), 2.3-1.6(4 \mathrm{H}, \mathrm{m}) .{ }^{13} \mathrm{C}-\mathrm{NMR}(200$ $\left.\mathrm{MHz}, \mathrm{CDCl}_{3}\right) \delta 158.7,141.6,130.6,129.7,125.3,124.1,110.8,109.9,35.4,20.4$; MS (70eV): m/z: 146(100), 145(26), 131(26), 117(40), 116(14), 115(41), 103(5.9), 91(16), 81(13), 58(28), 51(25), 50(10). Elemental Anal. Calc for $\mathrm{C}_{10} \mathrm{H}_{10} \mathrm{O}: \mathrm{C}, 82.16 ; \mathrm{H}, 6.89 ; \mathrm{O}, 10.94$. Found: C, 82.72; H, 6.27; O, 11.01.

3-(2-Furyl)-l-cyclohexanone (10). ${ }^{29} \mathrm{H}-\mathrm{NMR}\left(500 \mathrm{MHz}, \mathrm{CDCl}_{3}\right), \delta 7.2(1 \mathrm{H}, \mathrm{dd}, \mathrm{J}=1.80 .8 \mathrm{~Hz})$, $6.2(1 \mathrm{H}, \mathrm{dd}, \mathrm{J}=3.31 .8 \mathrm{~Hz}), 6(1 \mathrm{H}, \mathrm{dt}, \mathrm{J}=3.30 .8 \mathrm{~Hz}) 3.1-3.2(1 \mathrm{H}, \mathrm{m}) 2.68(1 \mathrm{H}, \mathrm{dd}, \mathrm{J}=14 \mathrm{~Hz}$, $4.6 \mathrm{~Hz}), 2.53(1 \mathrm{H}, \mathrm{ddd}, \mathrm{J}=14 \mathrm{~Hz}, 10 \mathrm{~Hz}, 1 \mathrm{~Hz}), 2.3-2.4(2 \mathrm{H}, \mathrm{m}), 2-2.19(1 \mathrm{H}, \mathrm{m}), 1.9-2.0(1 \mathrm{H}$, m), 1.8-1.9 (1H, m), 1.7-1.8 (1H, m). ${ }^{13} \mathrm{C}-\mathrm{NMR}\left(500 \mathrm{MHz}, \mathrm{CDCl}_{3}\right) \delta 24.4,29.9,37.6,41.3,45.6$, 104.5, 110.1, 141.3, 157.1, 210.1; MS (70eV): m/z: 164(35), 136(2), 121(27), 108(20), 107(100), 95(11), 94(59), 83(21), 82(24), 81(22), 79(42), 77(27), 70(16), 66(35), 65(37), 55(19), 42(51). 


\section{References and Notes}

1. (a) Daia, D. E; Gabbutt, C. D.; Heron, B. M.; Hepworth, J. D.; Hursthouse, M. B.; Malik, K. M. A. Tetrahedron Lett. 2003, 44, 1461. (b) Krause, N. Modern Organocopper Chemistry, Wiley-VCH: Weinheim, 2002.

2. Bertz, S. H.; Carlin, C. M.; Deadwyler, D. A.; Murphy, M. D.; Oglew, C. A.; Seagle, P. H. J. Am. Chem. Soc. 2002, 124, 13650.

3. Dieter, R. K.; Watson, R. T.; Goswami, R. Org. Lett. 2004, 6, 253.

4. Prat, D.; Benedetti, F.; Bouda, L. N.; Girard, G. F. Tetrahedron Lett. 2004, 45, 765.

5. (a) Gree, R.; Yadav, J. Chem. Rev. 2007, 107, 3286. (b) Martynow J.; Jozwik J.; Szelejewski W. Eur. J. Org. Chem. 2007, 4, 689. (c) Park, O.; Jung, J. Z. Naturforsch. 2007, 62b, 556.

6. Simonelli, F.; Oliveira, A.; Villar, J.; Gariani, R.; Wosch, C.; Zarbin, P. Tetrahedron Lett. 2007, 48, 1507.

7. (a) Spiga, M.; Secci, F.; Piras, P.; Ollivier, J.; Frongia, A.; Bernard, A. Tetrahedron 2007, 63, 4968. (b) Vila C.; Pedro, J.; Muñoz, C.; Molina, E.; Fernandez, I.; Blay, G. Tetrahedron 2006, 62, 8069.

8. (a) Garcia, G. V.; Nudelman, N. S. Org. Prep. \& Proc. Int. 2003, 35, 445. (b) Vazquez, A.; Goldberg, R.; Nudelman, N. S. In The Chemistry of Organolithium Compounds. Organolithiums as useful synthetic intermediates for tandem reactions; Rappaport Z.; Marek I. Eds.; Wiley: Chichester, 2005; Vol. 2, Chap. 2, pp. 63-137.

9. Nicolau, K. C.; Yue, E. W.; Oshima, T. In The New Chemistry. New Roads to Molecular Complexity; N. Hall, Ed.; Cambridge University Press: Cambridge, U.K., 2000; Chap. 8, p 178.

10. (a) House, H. O.; Respess, W. L.; Whitesides, G. M. J. Org. Chem. 1966, 31, 3128. (b) Whitesides, G. M.; Fischer, W. F.; San Filippo, R. W.; Bashe, H. O. J. Am. Chem. Soc. 1969, 91, 4871 .

11. Lipshutz, B. H.; Kayser, F.; Liu, Z-P. Angew. Chem. Int. Ed. Engl. 1994, 33, 1842. (b) Lipshutz, B. H.; Wood, M. R. J. Am. Chem. Soc. 1994, 116, 11689 and refs. therein.

12. Snyder, J. P.; Bertz, S. H. J. Org. Chem. 1995, 60, 4312.

13. Lipshutz B. H.; James, B. J. Org. Chem. 1994, 59, 7585.

14. Boche, G.; Bosol, F.; Loherenz, J. C. W. Angew. Chem. Int. Ed. Engl. 1994, 33, 1161.

15. Krause, N. Angew. Chem. Int. Ed. Engl. 1999, 38, 79.

16. (a) Corey, E. J.; Posner, G. H. J. Am. Chem. Soc. 1967, 89, 3911. (b) Corey, E. J.; Posner, G. H. J. Am. Chem. Soc. 1968, 90, 5615.

17. House, H. O.; Chu, C-Y.; Wilkins, J. M.; Umen, M. J. J. Org. Chem. 1975, 40, 1460.

18. Bertz, S. H.; Dabbagh, G.; Williams, L. M. J. Org. Chem. 1985, 50, 4414.

19. (a) Corey, E. J.; Boaz, N. W. Tetrahedron Lett. 1985, 26, 6015. (b) Corey, E. J.; Boaz, N. W. Tetrahedron Lett. 1985, 26, 6019. (c) Corey, E.J.; Hannon, F. J.; Boaz, N. W. Tetrahedron 1989, $45,545$. 
20. (a) Kuwajima I.; Komatsu M.; Horiguchi Y. Tetrahedron Lett. 1989, 30, 50, 7087. (b). Bertz, S. H.; Dabbagh, G. Tetrahedron 1989, 45, 425 (c) Bertz, S. H.; Smith, R.A. J., Tetrahedron 1990, 46, 4091.

21. Lipshutz B.; Dimock S.; James B. J. Am. Chem. Soc. 1993, 115, 9283.

22. Snyder J.; Rossieter B.; Miao G.; Bertz S. J. Am. Chem. Soc. 1995, 117, 11023.

23. Shriver, D. F. The Manipulation of Air-Sensitive Compounds; Wiley: New York, 1989.

24. Vitale, A. A.; Doctorovich, F.; Nudelman, N. S. J. Organomet. Chem. 1987, 332, 9.

25. Trzupek, L. S.; Newirth, T. L.; Kelly, E. G.; Nudelman, N. S.; Whitesides, G. M. J. Am. Chem. Soc. 1973, 95, 8118.

26. Nudelman, N. S.; Carro, C. Synlett 1999, 12, 1942.

27. NIST Data Center Collection (C) 2007 copyright by the U.S. Secretary of Commerce on behalf of the United States of America. All rights reserved.

28. SDBSWeb : http://riodb01.ibase.aist.go.jp/sdbs/ (National Institute of Advanced Industrial Science and Technology, May 2008).

29. Ng, J. S.; Behling, J. R.; Campbell, A. L.; Nguyen, D.; Lipshutz, B. Tetrahedron Lett. 1988, 29,3045 . 